\title{
Rubrik Moerangkalih dalam Surat Kabar Sipatahoenan sebagai Sarana Edukasi pada Tahun 1935
}

\author{
Lulu Liani, Asep Ahmad Hidayat \\ Fakultas Adab dan Humaniora, Universitas Islam Negeri Sunan Gunung \\ Djati Bandung \\ Email: lulu.liani297@gmail.com
}

\begin{abstract}
The development of the press cannot be separated from the emergence of the idealism of the nation's struggle to achieve independence. One effort to achieve this is by publishing appropriate readings for the nation's successors. This was done by the Pagoejoeban Pasoendan organization which published a special rubric named moerangkalih in the Sipatahoenan newspaper. This study aims to determine the history of the establishment of the Sipatahoenan newspaper in 1922-1935 and find out the educational discourse in the rubric of Moerangkalih Sipatahoenan newspaper in 1935. The method used is a historical research method with four stages namely heuristics, criticism, interpretation and historiography. The results of this study Sipatahoenan was from the results of the Pagoejoeban Pasoendan conference on 25-26 December 1922 to be published under the leadership of Ahmad Atmaja Pagoejoeban Pasoendan, Tasikmalaya Branch. On April 29, 1931 Sipatahoenan was transferred to the central board so that a moerangkalih rubric was published which contained appropriate reading for children at that time. Educational elements that can be found include educating readers to better appreciate life, the way to achieve the glory of life, as well as stories that have moral values in it such as how bad deeds someone does will return to him and the consequences of lazy deeds done continuously and repeatedly.
\end{abstract}

Keyword: Newspaper, press, education means 
Rubrik Moerangkalih dalam Surat Kabar Sipatahoenan sebagai Sarana Edukasi pada Tahun 1935 |Lulu Liani

\section{Pendahuluan}

Setiap organisasi perjuangan di Indonesia pada masa penjajahan Belanda memiliki media perjuangannya masing-masing yang menjadi corong bagi organisasinya. Pagoejoeban Pasoendan merupakan salah satunya. Organisasi ini menerbitkan majalah Pasoendan sejak 1915 dan surat kabar harian Sipatahoenan sejak 1923. ${ }^{1}$ Dari kedua terbitan yang dikeluarkan oleh Pagoejoeban Pasoendan ini masing-masing memiliki fokus pemberitaan yang berbeda. Surat kabar Pasoendan lebih menitik beratkan pemberitaan terkait dengan kiprah serta menyebarkan pikiran organisasi Pagoejoeban Pasoendan. Sedangkan Sipatahoenan lebih menitik beratkan pemberitaan umum biasanya tanpa campur tangan kepentingan organisasi Pagoejoeban Pasoendan. $^{2}$

Pada awalnya Sipatahoenan terbit hanya diedarkan di kota Tasikmalaya dan sekitarnya, kemudian meluas sampai seluruh Priangan, selanjutnya ke hampir seluruh Jawa Barat, bahkan dibaca pula di Surabaya dan Makassar. ${ }^{3}$ Sipatahoenan kemudian berkembang dengan baik Pada tahun 1919 Sipatahoenan terbit dua kali seminggu, dan sejak tahun 1930 menjadi harian. Sipatahoenan makin hari makin berkembang bersamaan dengan berkembangnya pergerakan nasional sehingga seringkali memuat artikel-artikel politik. ${ }^{4}$

Sipatahoenan kemudian berkembang dari segi kualitas isi relevansi tulisan maupun tempo terbitnya. Sipatahoenan juga mengeluarkan rubrik khusus kebudayaan (Kaboedajaan) setiap Rabu dan rubrik khusus anak-anak (Moerangkalih) yang terbit setiap Kamis kemudian berubah menjadi terbit setiap Sabtu.

Diterbitkannya rubrik khusus moerangkalih ini sebagai upaya penyelenggaraan pendidikan yang merupakan salah satu tujuan didirikannya Pagoejoeban Pasoendan. Moerangkalih merupakan bacaan selingan bagi anak-anak dari pengajaran di sekolah maupun di rumah oleh para orang tua.

${ }^{1}$ I Ketut Ardhana, Pergerakan Nasional dan Sistem Kepartaian, Indonesia dalam Arus sejarah Jilid 5 : Masa Pergerakan Kebangsaan, (Jakarta: Ichtiar Baru van Hoeve, 2009), 386.

${ }^{2}$ Pikiran Rakyat, 3 Februari 2015, "Sipatahoenan: Riwayat Koran Tiga Zaman”.

3 R. Djaka Soeryawan, Sejarah Berdirinya Paguyuban Pasundan, (Bandung: Lembaga Kebudayaan Universitas Pasundan, 1990), 37.

${ }^{4}$ Soeryawan, 38. 
Rubrik khusus ini sebagai upaya untuk membuat bacaan yang cocok dibaca oleh anak-anak pada masa itu. Tentunya bacaan anak pun harus dipilih berdasarkan asas manfaat yang nantinya akan dirasakan sang anak.

Rubrik moerangkalih diperuntukan bagi anak-anak yang saat itu sudah bisa membaca terutama anak yang berada di kelas 3 sekolah desa, sekolah Vervolg, HIS hingga anak yang berada di kelas 7 HIS. Isi dari rubrik ini berbagai macam pengetahuan mulai dari kisah teladan, pupuh, dongeng, sejarah hingga informasi-informasi mendidik lainnya.

\section{Metode}

Penelitian ini menggunakan metode penelitian sejarah untuk menguji dan menganalisa secara kritis rekaman-rekaman serta peninggalan masa lalu yang terdiri empat tahapan yaitu heuristik, kritik, interpretasi dan historiografi. $^{5}$

Heuristik, tahap heuristik merupakan kegiatan mencari sumber untuk mendapatkan data-data atau materi sejarah, atau evidensi sejarah. Pada tahapan ini, kegiatan diarahkan pada penjajakan, pencarian, dan pengumpulan sumber-sumber yang akan diteliti, baik yang terdapat di lokasi penelitian, temuan benda maupun sumber lisan. ${ }^{6}$ Pada tahapan ini, penulis mencari serta menghimpun sumber-sumber yang dianggap relevan dengan topik yang akan dibahas. Penulis menemukan berbagai sumber baik sumber primer maupun sumber sekunder yang dapat dijadikan rujukan dalam proses penyusunan skripsi adalah sebagai berikut:

Sumber berupa koran:

1) Rubrik Moerangkalih dalam Sipatahoenan edisi 3 hingga 30 Januari 1935.

2) Rubrik Moerangkalih dalam Sipatahoenan edisi 7 hingga 26 Februari 1935.

3) Rubrik Moerangkalih dalam Sipatahoenan edisi 7 hingga 30 Maret 1935.

4) Rubrik Moerangkalih dalam Sipatahoenan edisi 6 hingga 19 April 1935.

5) Rubrik Moerangkalih dalam Sipatahoenan edisi 4 hingga 25 Mei 1935.

\footnotetext{
${ }^{5}$ Gottschalk, Louis, Mengerti Sejarah, (Jakarta: UI Press, 1985), 32.

${ }^{6}$ Sulasman, Metodologi Penelitian Sejarah, (Bandung: Pustaka Setia, 2014), 93.
} 
Rubrik Moerangkalih dalam Surat Kabar Sipatahoenan sebagai Sarana Edukasi pada Tahun 1935 |Lulu Liani

6) Rubrik Moerangkalih dalam Sipatahoenan edisi 1 hingga 29 Juni 1935.

7) Rubrik Moerangkalih dalam Sipatahoenan edisi 6 hingga 27 Juli 1935.

8) Rubrik Moerangkalih dalam Sipatahoenan edisi 3 hingga 30 Agustus 1935.

Kemudian sumber berupa buku yaitu:

Buku Sejarah Berdirinya Paguyuban Pasundan ditulis R. Djaka Soeryawan dan diterbitkan Lembaga Kebudayaan Universitas Pasundan. Buku ini membahas tentang sejarah berdirinya Pagoejoeban Pasoendan, buku merupakan koleksi Dinas Perpustakaan dan Kearsipan Daerah Jawa Barat (DISPUSIPDA).

Buku Perjoangan Paguyuban Pasundan 1914-1942 ditulis Sjarif Amin dan diterbitkan Pustaka Jaya. Buku ini membahas mengenai Pagoejoeban Pasoendan secara umum mulai dari sejarah hingga pencapaiannya hingga tahun 1942. Buku ini merupakan koleksi Dinas Perpustakaan dan Kearsipan Daerah Jawa Barat (DISPUSIPDA).

Selanjutnya yaitu tahapan kritik. Pada tahapan ini yang dilakukan adalah untuk menentukan otentisitas dan kredibilitas atas sumber yang didapatkan dengan kualifikasi atas bentuk, bahan dan jenis dari naskah atau dokumen yang nantinya menentukan bagaimana validitas teks dan isi dari data-data. Dalam hal ini, dilakukan penyeleksian apakah data tersebut akurat atau tidak, baik dari segi bentuk maupun isinya sehingga dapat dipertanggungjawabkan. ${ }^{7}$ Tahapan kritik ini dibagi menjadi dua yaitu kritik intern dan ekstern.

Kritik ekstern digunakan untuk meneliti otentisitas sumber secara bentuk dengan menguji material kertas atau bahan, tanggal, dan tanda yang terdapat di dalam teks. ${ }^{8}$ Kritik internal menekankan kritik pada aspek isi dari sumber yang didapat. Setelah fakta kesaksian (fact of testimony) ditegakkan melalui kritik eksternal, tiba gilirannya untuk mengadakan evaluasi terhadap kesaksian itu, dan memutuskan apakah kesaksian itu dapat diandalkan (realible) atau tidak. ${ }^{9}$

${ }^{7}$ Abdurrahman, Dudung, Metode Penelitian Sejarah, (Jakarta: PT Logos Wacana Ilmu, 1999), 11.

${ }^{8}$ Kuntowijoyo, Pengantar Ilmu Sejarah, (Yogyakarta: Tiara Wacana, 2013), 77.

${ }^{9}$ Sjamsuddin, Helius, Metodologi Sejarah, (Yogyakarta: Penerbit Ombak, 2007), 91. 
Rubrik Moerangkalih dalam Surat Kabar Sipatahoenan sebagai Sarana Edukasi pada Tahun 1935 |Lulu Liani

Setelah melakukan kritik ekstern dan intern terhadap sumber yang terkumpul mengenai pembahasan sejarah Sipatahoenan tahun 1922-1935 dan wacana pendidikan dalam rubrik Moerangkalih surat kabar Sipatahoenan tahun 1935, kemudian sumber dikelompokkan menjadi sumber primer dan sekunder.

Sumber primer

1) Rubrik Moerangkalih dalam Sipatahoenan edisi 3 hingga 30 Januari 1935.

2) Rubrik Moerangkalih dalam Sipatahoenan edisi 7 hingga 26 Februari 1935.

3) Rubrik Moerangkalih dalam Sipatahoenan edisi 7 hingga 30 Maret 1935.

4) Rubrik Moerangkalih dalam Sipatahoenan edisi 6 hingga 19 April 1935.

5) Rubrik Moerangkalih dalam Sipatahoenan edisi 4 hingga 25 Mei 1935.

6) Rubrik Moerangkalih dalam Sipatahoenan edisi 1 hingga 29 Juni 1935.

7) Rubrik Moerangkalih dalam Sipatahoenan edisi 6 hingga 27 Juli 1935.

8) Rubrik Moerangkalih dalam Sipatahoenan edisi 3 hingga 30 Agustus 1935.

Sumber sekunder

1) Buku Sejarah Berdirinya Paguyuban Pasundan ditulis R. Djaka Soeryawan dan diterbitkan Lembaga Kebudayaan Universitas Pasundan. Buku ini diterbitkan tahun 1990 sehingga penulis memasukan ke dalam sumber sekunder walaupun isi dari buku ini cukup lengkap.

2) Buku Perjoangan Paguyuban Pasundan 1914-1942 ditulis Sjarif Amin dan diterbitkan Pustaka Jaya. Buku ini diterbitkan tahun 2003 sehingga penulis memasukan ke dalam sumber sekunder walaupun isi dari buku ini cukup lengkap.

Selanjutnya, Interpretasi adalah penafsiran data atau disebut juga analisis sejarah, yaitu penggabungan atas sejumlah fakta yang telah diperoleh. Tujuan dari analisis ini yaitu untuk melakukan sintesis atas sejumlah fakta yang diperoleh sebelumnya dari sumber-sumber sejarah dan 
bersamaan dengan teori-teori disusunlah fakta itu dalam suatu interpretasi secara menyeluruh. ${ }^{10}$

Dalam hal ini penulis mengggunakan teori informasi dengan menggunakan pendekatan komunikasi massa serta pendekatan analisis wacana. Pengertian yang mengarah pada perkembangan teori informasi (information theory) adalah pemahaman bahwa 'semua proses yang dapat dikatakan mentransfer informasi pada dasarnya adalah proses seleksi'. Sebagian besar penerapan teori ini lebih digunakan kepada jenis konten yang 'informatif' misalnya berita. ${ }^{11}$

Selanjutnya, Tahapan Historiografi merupakan tahapan berupa kegiatan penulisan hasil penafsiran atas fakta-fakta dan usaha merekontruksi masa lampau untuk memberikan jawaban atas masalah- masalah yang telah dirumuskan setelah sumber yang ditemukan pada tahapan heuristik, kemudian melewati tahap kritik dan interpretasi. Dengan demikian historiografi adalah tahapan lanjutan dari interpretasi yang kemudian hasilnya dituliskan menjadi suatu kisah yang menarik dan selaras. ${ }^{12}$

\section{Results and Discussions}

\section{Surat Kabar Sipatahoenan Tahun 1922-1935}

Surat kabar Sipatahoenan merupakan salah satu media lokal Sunda yang diterbitkan pada masa penjajahan Belanda dibawah bendera organisasi Pagoejoeban Pasoendan. Sipatahoenan berasal dari nama leuwi (lubuk) yang terdapat di Pakuan Padjadjaran. Tempat tersebut dianggap istimewa karena pernah digunakan oleh Prabu Siliwangi semasa kecil sebelum naik tahta kerajaan.

Sipatahoenan lahir dari hasil konferensi Pagoejoeban Pasoendan pada tanggal 25-26 Desember 1922 yang dihadiri oleh Bakrie Soeraatmadja, Kosasih Soerakoesoemah, Soekarja Prawiraamidjaja, dan Kadmirah Karnadidjaja. Kemudian tugas untuk mendirikan surat kabar Sipatahoenan ini dibebankan kepada Pagoejoeban Pasoendan Cabang Tasikmalaya dibawah pimpinan Ahmad Atmaja. ${ }^{13}$

${ }^{10}$ Sulasman, 107.

11 McQuail, Denis, Teori Komunikasi Massa, (Jakarta: Penerbit Salemba Humanika, 2011), 90.

${ }^{12}$ Lubis, Nina Herlina, Metode Sejarah, (Jawa Barat: YMSI. 2007), 55.

${ }^{13}$ Pikiran Rakyat, 3 Februari 2015, "Sipatahoenan: Riwayat Koran Tiga Zaman”. 
Rubrik Moerangkalih dalam Surat Kabar Sipatahoenan sebagai Sarana Edukasi pada Tahun 1935 |Lulu Liani

Sipatahoenan diterbitkan dengan uang pinjaman dari schoolfonds (dana beasiswa) Pasoendan sebagai modal awal penerbitannya. Sipatahoenan memiliki modal awal sekitar Rp 3.500 (setara gulden). Koran selanjutnya dijual dengan harga langganan Rp 1,5 sebulan atau Rp 4,5 per kuartal. Untuk luar Indonesia, harganya Rp 6 (tidak dijelaskan apakah per bulan atau per tiga bulan). Namun dalam hitungan hari, utang untuk modal awal penerbitan sudah bisa dilunasi. Hal ini terjadi karena Sipatahoenan menerapkan aturan kepada para pelanggannya untuk membayar di muka uang. ${ }^{14}$

Berita yang dimuat di surat kabar Sipatahoenan berasal dari berbagai daerah di Hindia Belanda. Untuk Berita luar negeri dipasok dari kontributor Sipatahoenan di Tokyo, Manila, dan Eropa (kebanyakan di Belanda). Berita lainnya didapat dari kantor berita Nera (Nieuws-en Reclame Agentschap) dan Aneta (Algemeen Nieuws en Telegraaf Agent Schap). ${ }^{15}$

Edisi pertama Sipatahoenan resmi terbit tanggal 20 April 1923. Kemudian Sipatahoenan memiliki kantor sendiri di Pasarkolot (Kalijaga), masih di Tasikmalaya. pada masa awal penerbitan ini Sipatahoenan masih berupa mingguan, sesuai amanat dari Bandung sebelumnya. Edisi ini dicetak di percetakan "Galoenggoeng" milik Obal Sobari atau Haji Sobari di Tasikmalaya. Pada awal penerbitannya Sipatahoenan hanya beredar di kota Tasikmalaya dan sekitarnya, namun kemudian peredarannya meluas hingga hampir seluruh Hindia Belanda. ${ }^{16}$

Pada tahun 1923 Sipatahoenan terbit satu kali dalam seminggu, kemudian pada tahun 1926 Sipatahoenan terbit dua kali seminggu yaitu rabu dan sabtu, hingga pada tahun 1930 Sipatahoenan resmi menjadi surat kabar harian. Pada tanggal 29 April 1931 pengurus Pagoejoeban Pasoendan cabang Tasikmalaya mengambil keputusan untuk menyerahkan Sipatahoenan kepada Pengurus Besar Pagoejoeban Pasoendan di Bandung. ${ }^{17}$

Di bawah pengelolaan Pengurus Besar Pagoejoeban Pasoendan Kantor redaksi pun berpindah dari Tasikmalaya ke Bandung dan berkantor di Jalan Kaca-kaca Wetan. Pada tahun 1933 kantor kemudian dipindahkan ke Jalan Banceuy. Untuk meningkatkan kinerjanya kemudian pada tahun 1934

\footnotetext{
${ }^{14}$ Pikiran Rakyat, 4 Februari 2015, "Digaji Hatur Nuhun".

${ }^{15}$ Pikiran Rakyat, 8 Februari 2015, "Kritik Sekaligus Toleran”.

${ }^{16}$ Pikiran Rakyat, 4 Februari 2015, "Digaji Hatur Nuhun".

${ }^{17}$ R. Djaka Soeryawan, 38-39.
} 
Rubrik Moerangkalih dalam Surat Kabar Sipatahoenan sebagai Sarana Edukasi pada Tahun 1935 |Lulu Liani

kantor redaksi berpindah lagi ke Moskeeweg (Jalan Dalem Kaum sekarang). ${ }^{18}$

Pagoejoeban Pasoendan sendiri memiliki tujuan untuk mengembangkan bahasa Sunda, membangkitkan perhatian terhadap sejarah dan asal Sunda, serta meningkatkan pengetahuan kehidupan rakyat di tanah Sunda. Oleh sebab itu selain didirikannya berbagai sekolah di bawah organisasi Pagoejoeban Pasoendan, Sipatahoenan sebagai juga mengeluarkan rubrik khusus yang diperuntukkan bagi anak-anak yang dinamakan Moerangkalih.

Dalam kata pengantarnya, disampaikan bahwa penerbitan aoseun moerangkalih yang merupakan bagian dari surat kabar Sipatahoenan ini sebagai penunjang disela-sela pelajaran di sekolah. Dibandingkan membaca bacaan bagi orang dewasa, lebih baik jika disajikan secara khusus bacaan untuk anak-anak yang layak.

\section{Wacana Pendidikan dalam Rubrik Moerangkalih Surat Kabar Sipatahoenan Tahun 1935}

Surat kabar sebagai salah satu media yang menyediakan berbagai informasi, tentunya memiliki sajian yang sangat beragam. Salah satu topik utamanya yaitu pendidikan. Melalui sebuah pemberitaan, pendidikan memungkinkan untuk dikaji oleh berbagai kalangan. Hal ini sejalan dengan fungsi media pers yaitu fungsi menyiarkan informasi, fungsi mendidik, fungsi menghibur, dan fungsi mempengaruhi. ${ }^{19}$

Rubrik moerangkalih yang merupakan bagian dari surat kabar Sipatahoenan ini memuat informasi pendidikan yang lebih banyak. Hal ini dikarenakan fokus utama diterbitkannya rubrik moerangkalih adalah untuk menyediakan bacaan yang layak untuk anak-anak pada masa itu yang tentunya juga mendidik mengandung nilai-nilai kebaikan serta moral ajaran Islam pada umumnya. Berikut ini bentuk-bentuk artikel yang dimuatnya:

1) Artikel utama

${ }^{18}$ Lubis, Nina, SI JALAK HARUPAT: Biografi R. Oto Iskandar di Nata (18971945), (Jakarta: Gramedia Pustaka Utama, 2003), 105-106.

${ }^{19}$ Effendy, Onong Uchjana, Ilmu Komunikasi (Teori dan Praktek), (Bandung: PT. Remaja Rosdakarya, 2007), 149. 
Rubrik Moerangkalih dalam Surat Kabar Sipatahoenan sebagai Sarana Edukasi pada Tahun 1935 |Lulu Liani

Kolom ini memiliki tema yang bermacam-macam, namun pada intinya mengedukasi pembacanya dengan pesan-pesan mengenai kehidupan baik itu berupa pesan keagamaan hingga pesan moral.

\section{Pibekeleun Hiroep}

Pangperloena pikeun oerang hiroep sangkan pinanggih djeung kamoeljaan koedoe: tjageur, bageur djeung pinter (kapinteran, kasehatan, kalakoean).

Ieu noe tiloe roepa koedoe diichtiaran ti ajeuna sangkan tiloeanana kapibanda koe oerang, sabab lamoen ti antarana (sala sahidji) henteu kapibanda, dina hiroepna moal sampoerna, oempamana ngan tjageur djeung pinter woengkoel, atawa pinter djeung bageur woengkoel, soemawonna lamoen ngan kapibanda saroepa atawa henteu pisan mah, kawas pangtjilaka-tjilakana.

Koe sabab eta meungpeung laleutik keneh eta noe tiloe roepa tea koedoe dibiasakeun ti ajeuna.

$$
\text { **...] }
$$

Tah, moeng sakitoe anoe emoet mah kasaoeranana djoeragan Goeroe teh, sarta dina noetoepkeunnana andjeuna sasaoeran kieu:

"Lain ari oedjoeb mah, ngan jakin jen lamoen eta noe tiloe roepa (tjageur-bageur-pinter) koe maneh bisa kapibanda Insja-Allah, hiroep maneh bakal pinanggih djeung kamoeljaan"

\section{[...]}

Panoetoep pihatoer ti abdi sabatoer-batoer, oendjoek reboe-reboe noehoen $k a$ djoeragan Redacteur Sipatahoenan, wireh parantos masihan tempat kanggo ieu karangan dina Sipatahoenan bagian aoseun "Moerangkalih"

Baktosna

Moerid-moerid kl. IV di

Schakelschool Pasoendan

LELES

(Sipatahoenan: Moerangkalih, Saptoe 15 Juni 1935, No.133 Lambaran ka 1)

\section{Bekal Kehidupan}


Hal yang diperlukan bagi kita dalam hidup agar mendapat kemuliaan harus: sehat, baik dan pintar (kepintaran, kesehatan, perbuatan).

Tiga hal tersebut harus diusahakan dari sekarang agar bisa kita miliki, sebab jika diantaranya (salah satunya) tidak dimiliki, dalam hidup tidak akan sempurna, umpama hanya sehat dan pintar saja, atau pintar dan baik saja, apalagi jika hanya memiliki satu atau tidak sama sekali akan sangat berbahaya.

Oleh sebab itu selagi masih kecil, tiga hal tadi harus dibiasakan dari sekarang.

\section{$[\ldots]$}

***

Hanya sekian yang dapat diingat dari perkataan pak guru sebelumnya, juga saat menutup penjelasan beliau berkata begini:

"Bukan kita merasa takabur, namun yakinlah jika ketiga hal yang tadi (sehat-baik-pintar) apabila kalian miliki insya-Allah, hidup kalian akan mendapatkan kemuliaan"

\section{[...]}

Penutup dari saya dan kawan-kawan, mengucapkan beribu-ribu terima kasih kepada Redaktur Sipatahoenan yang telah memberikan kesempatan untuk karangan ini diterbitkan di Sipatahoenan bagian bacaan "Moerangkalih"

Bakti Murid-murid kl. IV di Schakelschool Pasoendan LELES

(Sipatahoenan: Moerangkalih, Sabtu 15 Juni 1935, No.133 Lembaran ka 1)

Dalam kutipan di atas yang berjudul "Pibekeleun Hiroep" memiliki arti bekal menjalani kehidupan. Dari kutipan tersebut, pembaca dimungkinkan untuk lebih memahami apa itu cageur, bageur, pinter. Hal-hal tersebut sangat kita perlukan dalam hidup agar hidup kita mendapatkan kemuliaan.

\section{Koedoe Sagala Wajahna}

\section{Baroedak!}

Sarerea oge meureun geus ngadenge ari bedja-bedja bae mah, jen ajeuna teh keur oesoem tigerat.

Ari noe diseboet tigerat teh, nja eta oesoem soesah njiar kahiroepan. 
Rubrik Moerangkalih dalam Surat Kabar Sipatahoenan sebagai Sarana Edukasi pada Tahun 1935 |Lulu Liani

Ari koe maraneh mah, koe baroedak tangtoe bae moal karasa, tapi koe kolot noe oesaha njiar kipajah keur dahar pake maraneh tang toe katjida karasana teh.

Nijan pakoelian ajeuna katjida hesena, oge barisa meunang pakoelian oge, ari boeroehna mah saeutik pisan.

\section{[...]}

Saha nu njaah ka kolot?

Abong lamoen henteu boba pikiran njaah ka kolot teh, maraneh koedoe roemasa ti keur djadi orok nepi ka sagede kieu teh, lantaran dimemenan koe kolot. Ema noe ngarawatanana, ari bapa noe poerah oesahana, soepaja maneh walagri, nja ajeuna boekti nepi ka sagede kieu malah geus bisa sakola sagala, sanadjan teu atjan tamat oge.

Naon tandana njaah ka kolot?

Ari koedoe oesaha mantoean kolot mah tangtoe maraneh moal bisa da moal katanagaan tea. Djadi sanadjan ajeuna sakoemaha ripoehna oge, kolot maraneh dina oesahana henteu aja petana ari menta dibantoean ka maraneh mah.

\section{[...]}

Ajeuna maraneh geus gede, djadi geus meudjeuhna lamoen mimiti diadjar mikir kana kasoesahna noe djadi kolot tea.

Minengka pamoelang tarima maraneh kana kanjaahna kolot tea tjoekoep lamoen maneh getol kana diadjar bae, henteu ngaroengsing loba kahajang, henteu ogoan, henteu moemoelan.

Regepkeun!

(Sipatahoenan: Moerangkalih, Kemis 7 Februari 1935, No.29 Lambaran ka 1)

\section{Harus Mengerti Keadaannya}

Anak-anak!

Semua orang mungkin sudah pernah mendengar kabar, jika sekarang sedang musim tigerat.

Yang disebut tigerat yaitu musim susah mencari kehidupan.

Bagi seusia kalian mungkin tidak akan terasa, namun bagi orangtua yang sedang usaha mencari kehidupan (penghasilan) untuk makan kalian pasti sangat terasa sulitnya.

Mencari pekerjaan sekarang sulit, meskipun bisa mendapat pekerjaan tapi penghasilan yang didapat sangat kecil. 
Rubrik Moerangkalih dalam Surat Kabar Sipatahoenan sebagai Sarana Edukasi pada Tahun 1935 |Lulu Liani

[...]

Siapa yang sayang pada orang tua?

Jika kalian tidak punya pikiran untuk sayang pada orangtua, harusnya kalian merasakan bagaimana orangtua membesarkan kalian dari bayi hingga sebesar ini. Ibu yang merawat, sedangkan Ayah yang bekerja supaya kalian sehat walafiat, hal ini terbukti sekarang hingga kalian sebesar ini bahkan sudah bisa sekolah meskipun belum tamat.

Apa tandanya sayang pada orangtua?

Jika harus bekerja membantu orangtua mungkin kalian tidak akan bisa karena tidak cukup tenaga. Jadi meskipun seberapa susahnya orangtua kalian bekerja, mereka tidak berusaha untuk meminta bantuan kalian.

$[\ldots]$

Sekarang kalian sudah besar, jadi sudah saatnya untuk mulai belajar berpikir tentang susahnya menjadi orangtua.

Sebagai tanda terimakasih terhadap kasih sayang orangtua, cukup dengan kalian rajin belajar, tidak manja berlebihan banyak kemauan. Perhatikanlah!

(Sipatahoenan: Moerangkalih, Kamis 7 Februari 1935, No.29 Lembaran 1)

Dalam kutipan di atas yang berjudul "Koedoe Sagala Wajahna" memiliki arti harus mengerti keadaannya. Melalui tulisan ini pembaca disadarkan akan pentingnya menghargai kehidupan itu sendiri, menjadi seseorang yang lebih bersyukur terhadap apa yang telah orangtuanya perjuangkan untuknya.

2) Roepa-roepa kanjaho (Berbagai pengetahuan)

Kolom ini memiliki tema yang bermacam-macam, namun pada intinya memberikan pengetahuan yang baru bagi para pembacanya. Bahkan juga hal-hal yang sangat tidak terduga.

\section{Roepa-roepa kanjaho}

$[\ldots]$

V. Di wewengkon tanah Irak, aja hidji pasir anoe hantem bae dikali. Ajeuna geus kapanggih di dinja aja oeroet nagara, anoe moesna koe bahaja alam, bandjir gede, 4100 taoen samemeh djoemeneng Nabi Isa. 
Rubrik Moerangkalih dalam Surat Kabar Sipatahoenan sebagai Sarana Edukasi pada Tahun 1935 |Lulu Liani

Noeroetkeun panemoe anoe palinter, eta teh nagara anoe dina djaman ka-sawelas.

Djadi oerang ajeuna aja dina djaman anoe ka 12.(Sipatahoenan: Moerangkalih, Saptoe 3 Augustus 1935, No.175 Lambaran ka 1)

\section{Berbagai pengetahuan}

\section{[...]}

V. Di wilayah Irak, ada satu wilayah berpasir yang sering digali. Sekarang di tempat tersebut ditemukan bekas suatu negara yang musnah akibat bencana alam banjir bandang, 4100 tahun sebelum kelahiran Nabi Isa.

Menurut para penemu yang pandai, negara tersebut berada di jaman ke sebelas.

Jadi sekarang kita berada di jaman ke 12. (Sipatahoenan: Moerangkalih, Sabtu 3 Agustus 1935, No.175 Lembaran 1)

Dalam kutipan di atas yang berjudul "Roepa-roepa kanjaho", pembaca diinformasikan penemuan-penemuan baru pada masa itu yaitu dengan ditemukannya mesin tulis kecil yang dapat dibawa dalam perjalanan serta penemuan wilayah baru yang diperkirakan telah ada sejak 4100 sebelum kelahiran Nabi Isa di Irak namun mengalami kehancuran akibat bencana alam.

\section{Sato leuweung}

Noe njorang toempak kareta api ti Bandjar ka Pangandaran, sok radjeun lebah leuweungna nendjo loetoeng tinggoentajang.

Di Rhodesie-Kaler (taroekeun ka djoeragan goeroe), koe lantaran djalan kareta api ngaliwatan leuweung gerot, meureun noe ilahar diseboet leuweung ganggong simanggong tea, pohara remenna kadjadian aja singa, gadjah djeung banteng paraeh karoempak koe kareta api. (Sipatahoenan: Moerangkalih, Kemis 26 Februari 1935, No.47 Lambaran ka 1)

\section{Hewan di Hutan}

Orang yang pernah mengalami naik kereta dari Banjar ke Pangandaran, pasti kadang-kadang melihat ke arah hutan ada sekelompok lutung yang menggantung. 
Rubrik Moerangkalih dalam Surat Kabar Sipatahoenan sebagai Sarana Edukasi pada Tahun 1935 |Lulu Liani

Di Rhodesie-Kaler (tanyakan pada guru), dikarenakan kereta api yang melewati hutan besar, yang biasa disebut hutan belantara, betapa seringnya kejadian singa, gajah dan banteng mati tertabrak kereta api. (Sipatahoenan: Moerangkalih, Kamis 26 Februari 1935, No.47 Lembaran 1)

Dalam kutipan di atas yang berjudul "sato leuweung" memiliki arti hewan yang ada di hutan. Tulisan tersebut menginformasikan pembaca bahwa banyak hewan hutan yang mati karena tertabrak kereta api. Hal ini dapat pembaca simpulkan bahwa dari setiap pembangunan suatu fasilitas, akan mengorbankan sesuatu yang lain juga.

3) Toetoeroetjingan (Tebak-tebakan)

Dalam kolom ini para pembaca diajak untuk menebak kata atau kalimat apa yang dimaksud dalam suatu pernyataan. Bisa dikatakan kolom ini merupakan kolom hiburan di mana para pembaca diharuskan mengingat kembali apa yang telah ia ketahui selama ini.

\section{Toetoeroetjingan}

1. Dina naon oerang nendjo djelema, lamoen oerang wani - itoe wani. djeung lamoen oerang sieun-itoe oge sieuneun koe oerang.

2. Ti kadjaoehan koe oerang di boro-boro, ari geus deukeut diapilainkeun.

3. Hidji ketjap beunang dibagi doea, lamoen engang noe kahidji djadi noe kadoea karasana koe letah, tapi lamoen tetep, koe tjeuli.

4. Aja deui hidji ketjap, beunang dipake koe doea bangsa, tapi koedoe diganti aksarana noe di toekang, nja eta asalna i djadi a.

5. Kai sateukteuk digotong koe doeaan, koe noe koemaha?

[...]

(Sipatahoenan: Moerangkalih, Kemis 3 Januari 1935, No.2 Lambaran ka 1)

\section{Tebak-tebakan}

1. Menggunakan apa kita melihat orang, jika kita berani - dia juga berani, namun jika kita takut - dia juga akan takut pada kita.

2. Dari kejauhan kita kejar, tapi jika sudah dekat kita jauhkan.

3. Satu kata yang bisa dibagi dua, jika suku kata pertama menjadi suku kata kedua akan terasa di lidah, tapi jika tetap akan terdengar telinga. 
Rubrik Moerangkalih dalam Surat Kabar Sipatahoenan sebagai Sarana Edukasi pada Tahun 1935 |Lulu Liani

4. Ada pula satu kata tapi bisa dipakai oleh dua bangsa, tapi harus diganti konsonan akhirnya, yaitu dari i menjadi a.

5. Sepotong kayu digotong berdua, bagaimana caranya?

[...]

(Sipatahoenan: Moerangkalih, Kamis 3 Januari 1935, No.2 Lembaran 1)

\section{Toetoeroetjingan}

Ieu eusina toetoeroetjingan anoe Kemis toekang

No. 1 nja eta dina eunteung.

No. 2 nja eta lawang.

No. 3 nja eta Lagoe oepama dibalikeun djadi goela, enja henteu?

No. 4 nja eta ketjap lami, oepama i diganti koe a meureun jadi lama.

No. 5 nja eta koe noe lolong djeung noe noengtoen.

[...]

(Sipatahoenan: Moerangkalih, Kemis 10 Januari 1935, No.6 Lambaran ka 1)

\section{Tebak-tebakan}

Berikut ini isi dari tebak-tebakan Kamis minggu lalu.

No. 1 yaitu dari cermin.

No. 2 yaitu gerbang/pintu.

No. 3 yaitu Lagu jika dibalikan menjadi gula, iya kan?

No. 4 yaitu kata lami, apabila i diganti dengan a berubah jadi lama.

No. 5 yaitu orang buta yang juga orang yang menuntunnya.

[...]

(Sipatahoenan: Moerangkalih, Kamis 10 Januari 1935, No.6 Lembaran 1)

Untuk menjawab toetoeroetjingan ini tentunya diperlukan pengetahuan dasar bagi para pembaca. Namun sebenarnya toetoeroetjingan ini tidak terlalu sulit untuk dijawab karena semua pernyataannya berkaitan dengan benda maupun kejadian yang dapat kita lihat dalam kehidupan sehari-hari. Kutipan pertama merupakan edisi pertama berupa pernyataan tebak-tebakan sedangkan kutipan kedua merupakan jawaban dari toetoeroetjingan edisi sebelumnya.

4) Dongeng 
Rubrik Moerangkalih dalam Surat Kabar Sipatahoenan sebagai Sarana Edukasi pada Tahun 1935 |Lulu Liani

Dongeng adalah cerita yang tidak benar-benar terjadi, terutama kejadian yang terjadi pada jaman dulu yang dapat dikatakan aneh. ${ }^{20}$ Dongeng ini berfungsi sebagai hiburan serta sarana untuk mewariskan nilai-nilai yang diyakini kebenarannya oleh masyarakat pada masa itu. Biasanya dalam dongeng terdapat pesan moral yang disampaikan kepada para pembaca.

\section{Patjadoean}

Loba pisan djelema anoe sok tjadoe kana kadaharan atawa kana laoek noe soekoe opat, atawa noe tjadoe kana laoek manoek djapati.

Djaman baheula keur dajeuh kaboepaten Bandoeng masih keneh di Dajeuh-kolot di kampoeng Kamasan palebah Bandjaran ajeuna aja hidji kamasan anoe kamashoer kabisana.

[...]

Dina hidji mangsa kangdjeng Dalem kagoengan mata-ali anoe aloes kabina-bina.

Andjeunna teh hojong midamel lelepen. Toeloej Ki kamasan disaoer, sarta dawoehanana teh, lamoen ieu asli bisa anggeus dina djero doea powe, engke manehna dipersen doenja-barana anoe gede pisan.

Pangna kangdjeng Dalem hojong anggeus gantjang teh, doemeh rek dianggo kana pesta gede.

Koe Ki kamasan disanggoepan sarta toeloej balik.

Datang ka imahna njarita ka pamadjikanana, pokna teh: "pamadjikan! lamoen aja semah anoe sedjen, bedjakeun aing henteu bisa narima bae, lantaran koedoe njieun lelepen kagoengan Pangsiwoelaan"

Toeloej manehna teh asoep ka gasoli, mintoe maneh rek digawe.

Katjaritakeun eta kamasan teh boga anak leutik hidji, lalaki, toer dipikanjaah pisan. Tara teuing djaoeh tina toeoerna lamoen keur digawe teh.

Eta boedak tea kakara bisa ngarandang. Lamoen indoengna ka tjai atawa miroen seuneu, eta boedak teh sok dipihapekeun ka bapana sina ngabatoeran di gasoli.

Tapi waktoe harita mah ditjarek ka indoengna henteu meunang disina ka djero gasoli.

${ }^{20}$ Pusat Bahasa, Kamus Besar Bahasa Indonesia, (Jakarta: Balai Pustaka, 2007), 247. 
Rubrik Moerangkalih dalam Surat Kabar Sipatahoenan sebagai Sarana Edukasi pada Tahun 1935 |Lulu Liani

Barang geus sapowe ka doeana, watang ali teh geus anggeus, eta boedak tea koe indoengna dipihapekaun ka bapana doemeh manehna rek ka tjai.

Boedak teh oelin di gasoli. Ki kamasan tea hajang kiih. Toeloej toeroen.

Naha atoeh ana geleber teh aja djapati, eunteup dina tempat parabot, poetjak-patjok, ketjok kana mata ali kagoengan kangdjeng Dalem.

Barang datang deui kamasan ka djero gasoli, ali teh geus leungit.

Atoeh kaget, sarta lantaran teu aja deui djelema anoe asoep iwal ti boedak, anakna anoe keur ngarandang tea, euweuh deui sangkaanana teh ngan eta mata ali di tjokot koe boedak (anakna) tea.

Henteu anta parah deui toeloej eta boedak teh dipeuntjit sarta dibedel beuteungna, barang diilikan bet henteu aja naon-naon.

Geleber djapati noe tadi tea asoep deui ka djero gasoli bari poetjakpatjok.

Koe kamasan ditewak, ana dibedel teh telihna bet deusi eta mata ali anoe leungit tea.

Koe sabab kitoe, manehna pohara kedoehoengeunana, hanas boedak paeh dipeuntjit, lantaran sieun koe ratoe, ari ali kapanggih tina djero telih djapati.

Ti waktoe harita manehna teh bidjil tjarita (soepata) saanak-intjoena nepi ka toedjoeh toeroenan henteu meunang dahar laoek (manoek) djapati, sababna djapati teh geus ngalantarankeun paeh anakna anoe dipikameumeut pisan tea.

NANI

(Sipatahoenan: Moerangkalih, Kemis 30 Januari 1935, No.24 Lambaran ka 1-2)

\section{Sumpah}

Sangat banyak orang yang suka dengan suatu makanan atau hewan berkaki empat, atau suka makan burung merpati.

Pada jaman dahulu saat kota Kabupaten Bandung masih bertempat di Dayeuh Kolot di kampung Kamasan dekat Banjaran sekarang terdapat satu kamasan (tukang pembuat emas) yang sangat terkenal kemampuannya.

$[\ldots]$

Pada suatu waktu seorang bupati memiliki batu cincin yang sangat bagus. 
Beliau ingin membuat cincin. Kemudian Ki kamasan dipanggil, jika bisa selesai membuat cincin dalam waktu dua hari, nantinya Ki kamasan akan diberikan harta benda yang sangat banyak.

Alasan Bupati ingin selesai lebih awal dikarenakan cincinnya akan dipakai saat pesta besar diadakan.

Oleh Ki kamasan disanggupi kemudian pulang.

Sesampainya di rumah kemudian menceritakan pada istrinya, katanya: "Istriku! Jika ada tamu yang lain, beritau aku tak akan terima karena harus membuat cincin kepunyaan Bupati”

Kemudian beliau masuk ke gasoli (tempat bekerja panday), menutup pintu akan bekerja.

Diceritakan kamasan itu mempunyai seorang anak kecil, laki-laki, yang sangat disayanginya. Tak pernah jauh dari lutunya saat beliau sedang bekerja.

Anak itu baru bisa merangkak. Jika ibunya ke kamar mandi atau menyalakan api, anak tersebut dititipkan pada bapanya menemaninya di gasoli.

Tapi pada suatu waktu, ibunya dilarang tak boleh memasuki gasoli.

Pada hari kedua, batang cincin telah beres dikerjakan, anak itu oleh ibunya dititipkan pada bapanya sementara ia ke kamar mandi.

Anak itu main di gasoli. Sementara Ki kamasan pun turun dari gasoli untuk kencing.

Kemudian ada merpati terbang dalam gasoli, merpati itu hinggap di perabotan, mematuk apa saja yang ada hingga batu cincin kepunyaan Bupati pun tertelan.

Saat kamasan datang ke gasoli, batu cincin telah hilang.

Hal itu membuatnya kaget karena tak ada satu pun orang yang masuk kecuali anaknya yang sedang merangkak tadi, tak ada lagi sangkaannya kecuali batu cincin tadi diambil oleh anaknya.

Tak perlu pikir panjang kemudian anaknya ia sembelih serta ditembak perutnya, namun setelah diteliti ternyata tak ditemukan apapun.

Merpati yang tadi masuk kemudian terbang lagi ke dalam gasoli sambil mematuk apapun di dekatnya.

Kamasan pun menangkapnya, ditembak temboloknya dan ternyata berisi batu cincin yang sempat hilang. 
Oleh sebab itu, beliau sangat menyesal telah membunuh anaknya karena takut oleh Bupati, sementara batu cincinnya ditemukan di dalam tembolok merpati.

Sejak saat itu beliau menceritakan pada anak-cucunya sampai tujuh turunan tidak boleh memakan burung merpati, sebab merpati telah menyebabkan anak yang sangat disayanginya meninggal.

NANI

(Sipatahoenan: Moerangkalih, Kamis 30 Januari 1935, No.24 Lembaran 1-2)

Kutipan di atas berjudul "Patjadoean" yang memiliki arti sumpah. Maksud dari sumpah disini adalah adanya penyesalan yang mendalam dari tokoh utama yang telah melakukan suatu hal terlarang sehingga ia melakukan sumpah untuk tidak melakukannya lagi. Tulisan tersebut memberikan gambaran kepada pembaca tentang bagaimana seseorang sangat menyesali perbuatannya yang terburu-buru langsung menuduh suatu hal yang belum tentu terbukti kebenarannya, padahal seharusnya mengecek ulang prasangkanya.

\section{5) Toeladan}

Dalam kolom ini para pembaca disajikan kisah-kisah pendek namun memiliki nilai moral yang tinggi. Kisah yang disajikan merupakan kisah yang sangat ringan dan mudah dipahami namun memberikan teladan kepada para pembaca.

\section{Boedak Bangor}

Si Akrim boedak bangor, karesepna ngaheureujan batoer.

Roepa-roepa djalanna teh, tapi anoe pang dipikaresepna mah njingsieunan batoer.

Lamoen aja baroedak anoe gila koe hileud atawa koe lentah, sok dihadjakeun dioedag-oedag nepikeun ka djedjeritan.

Lamoen geus ripoeh mah batoerna tea, soeka bae manehna mah.

Dina hidji peuting manehna njingsieunan batoerna anoe balik ngaradji ti masigit. Ari Akrim njokot simboet paranti sarena, toeloej dikoeroedoengkeun. 
Rubrik Moerangkalih dalam Surat Kabar Sipatahoenan sebagai Sarana Edukasi pada Tahun 1935 |Lulu Liani

Dimana baroedak ngabroel, heg disampeurkeun bari garamgerem. Atoeh batoerna teh tjingdjarerit laloempatan, bari kokotjeakan:djoerig, djoerig!!

Soeka si Akrim hatena!

Koe lantaran dina peutingan ka hidji hasil maksoedna tea, peuting isoekna teh nja kitoe deui bae.

Ajeuna mah anoe dipake tioeng teh, moekena indoengna. Lain hawoek roepana teh, tapi bodas. Toeloej bari engklah-engklakan njingsieunan teh.

Kabeneran harita mah goeroe ngadjina bareng djeung baroedak boebarna ti masigit.

Barang nendjo anoe ngaringkiwik bodas, teu anta parah deui ngan habek bae diteunggeul koe iteuk.

Atoeh si Akrim teh tjeurik, adoeh-adoehan.

Tjek goeroe ngadji teh: "Tah, noe matak ari djadi boedak oelah sok tjilimit, daek ngaheureujan batoer, koemaha ari geus kitoe? Moal deui-deui maneh kikitoean?"

"Mo-o-o-a-a-a-al" djawabna Akrim bari tjeurik. (Sipatahoenan: Moerangkalih, Kemis 24 Januari 1935, No.18 Lambaran ka 2)

\section{Anak Nakal}

Si Akrim anak nakal, menjahili orang lain adalah kesukaannya.

Macam-macam caranya, tapi yang paling disukainya menakuti orang lain.

Jika ada anak-anak yang takut ulat atau lintah, dia sengaja mengejarnya hingga korbannya menjerit.

Jika temannya sudah kerepotan, dia sangat menyukainya.

Pada satu malam, dia menakuti temannya yang baru pulang dari pengajian di masjid. Sedangkan Akrim mengambil selimutnya kemudian di gunakan untuk menutupi tubuhnya.

Saat anak-anak bubar, ia menghampirinya sambil mendeham. Temannya kemudian menjerit sambil lari dan teriak: setan, setan!!

Si Akrim merasa sangat senang

Karena kemarin malam berhasil, keesokan harinya ia berbuat hal yang sama. 
Jika sebelumnya memakai selimut, sekarang ia memakai kerudung mukena milik ibunya yang berwarna putih. Lalu sambil meloncat-loncat untuk menakutinya.

Kebetulan pada waktu itu guru ngajinya keluar bersamaan dengan teman-temannya dari masjid.

Saat melihat ada makhluk putih, tak lama langsung dipukul tongkat oleh guru ngajinya.

Akrim pun mengaduh kesakitan.

Guru ngajinya berkata: "Nah ini akibat dari suka menggoda, mau menjahili orang lain, gimana kalau sudah begini? Kamu gak akan begini-begini lagi?"

"Ga-a-ak ak-an" jawab Akrim sambil nangis. (Sipatahoenan: Moerangkalih, Kamis 24 Januari 1935, No.18 Lembaran 2)

Kutipan di atas berjudul "boedak bangor" yang memiliki arti anak nakal. Kutipan tersebut bertujuan untuk memberikan teladan kepada para pembaca melalui kisah pendek yang dituliskan. Tulisan tersebut memberikan gambaran kepada pembaca tentang bagaimana perbuatan buruk yang dilakukan seseorang akan kembali kepadanya.

\section{6) Tamba manjoen}

Tamba manjoen ini memiliki arti lebih baik tersenyum. Maksud dari tamba manjoen ini adalah dari pada kita mengisi hari dengan cemberut lebih baik tersenyum karena membaca cerita yang disajikan. Dalam kolom ini disajikan cerita pendek namun lucu yang bisa membuat pembacanya tersenyum.

\section{Salah Mangarti}

Goeroe nanja ka moeridna anoe ngaran Samad pokna:

"Samad, tjoba dijawab pertanjaan dewek anoe bener, sarta teu koedoe boeroe-boeroe, beunang dipikiran heula: Sabaraha hidji ramona leungeun maneh anoe kentja?"

Samad teu talangke deui toeloej ngadjawab: "Soemoehoen lima ,

Goeroe: "heueuh! Bener, djeung sabara hidji ramona leungeun maneh noe katoehoe?"

Samad: "Soemoehoen lima keneh." 
Rubrik Moerangkalih dalam Surat Kabar Sipatahoenan sebagai Sarana Edukasi pada Tahun 1935 |Lulu Liani

Goeroe: "Heueuh, eta oge bener, ajeuna lima ramo anoe kentja ditambah lima ramo anoe katoehoe djadi sabaraha djoemblahna kabeh?"

Samad: "Djomlah sadajana ramo leungeun kentja sareng ramo leungeun katoehoe, djadi sapoeloeh."

Goeroe: "Heueuh eta oge bener keneh, tah ramo anoe sapoeloeh teh ditambah deui koe ramona si Ali anoe kentja reana lima, djadi sabaraha djoemblahna kabeh."

Samad: "Ah! doeka abdi mah seueur teuing, gadoeh sapoeloeh oge parantos tjekap."

Goeroe: "Har! Lain rek dibikeun ieu mah oepamana bae ramo maneh sapoeloeh ditambah ramo si Ali lima djadi djoemblahna sabaraha?"

Samad: "Sanadjan dipaksa oge moal ditambah deui da gadoeh sapoeloeh oge meudjeuhna."

Goeroe rada keroeng: "Heug kadjeun ari emboeng rea ramo mah, kieu bae ajeuna mah adi maneh ngabogaan kaletji sapoeloeh ditjokot koe si Ali opat, tinggal sabaraha sesana?"

Samad: "Oepama si Ali wani njokot kaletji poen adi, engke di tjabok koe abdi."

Goeroe seuri koneng bari gagaro. (Sipatahoenan: Moerangkalih, Kemis 14 Februari 1935, No.35 Lambaran ka 2)

\section{Salah Paham}

Guru bertanya pada murid yang bernama Samad, katanya:

"Samad, coba jawab pertanyaan saya dengan benar, tak perlu buruburu, boleh dipikirkan dulu: Berapa banyak jarimu di tangan kiri?"

Samad langsung menjawab: "Iya pak guru lima

Guru: "Iya! Benar, dan berapa banyak jarimu di tangan kanan?"

Samad: "Iya pak guru masih lima."

Guru: "Iya itu juga benar, sekarang lima jari yang di kiri ditambah lima jari yang di kanan jadi berapa jumlah semuanya?"

Samad: "Jumlah semuanya jari tangan kiri dan jari tangan kanan jadi sepuluh"

Guru: "Iya itu juga masih benar, nah jari yang sepuluh itu ditambah lagi jarinya si Ali yang kanan lima, jadi berapa jumlah semuanya?" 
Samad: “Ah! Gak tau pak terlalu banyak, punya sepuluh juga sudah cukup"

Guru: "Hei! Bukan jarinya mau diberikan sama kamu, jika jarimu sepuluh ditambah jarinya si Ali lima jadi jumlahnya berapa?"

Samad: "Meskipun dipaksa juga gak akan ditambah lagi, punya sepuluh pun sudah cukup."

Guru mengerutkan dahi: "Okey tak apa jika gak mau banyak jari, begini saja sekarang adikmu mempunyai kelereng sepuluh diambil si Ali empat, tinggal berapa sisanya?"

Samad: "Misal si Ali berani ngambil kelereng adikku, nanti akan ku tampar."

Guru pun tertawa sambil menggaruk tengkuk. (Sipatahoenan: Moerangkalih, Kamis 14 Februari 1935, No.35 Lembaran 2)

Dalam kutipan di atas diceritakan tentang guru yang bertanya penjumlahan pada muridnya dengan mengambil contoh penjumlahan jari tangan kiri dengan jari tangan kanan. Namun ternyata murid tersebut salah paham saat gurunya memintanya menambahkan sepuluh jarinya dengan lima jari temannya. ia tidak mau menjumlahkannya karena sudah merasa cukup hanya dengan sepuluh jari di tangannya sehingga tidak mau menambahkan lagi jarinya. Hingga saat gurunya memakai contoh lain pengurangan dengan pemisalan kelereng adiknya yang diambil temannya pun ia salah paham dan akan menampar temannya jika itu benar terjadi. Benar-benar salah paham maksud dari gurunya.

\section{7) Goegoejon (Guyonan/Lelucon)}

Goegoejon ini memiliki arti guyonan atau lelucon. Dalam kolom ini para pembaca disajikan cerita pendek yang sifatnya lucu. Kolom ini juga merupakan kolom hiburan selain toetoeroetjingan dan tamba manjoen. Dari beberapa judul yang ada, penulis memilih beberapa cerita goegoejon yang dirasa cukup menghibur.

\section{Paingan}

Oedjang Emen diboei 7 boelan, sabab maling hajam 7 siki.

Sanggeus kaloear ti boei koe batoerna, Si Machmoed, noe geus lila teu panggih djeung manehna, ditanja: "Men, tas ti mana silaing teh mani geus lila teu panggih djeung dewek?" 
Rubrik Moerangkalih dalam Surat Kabar Sipatahoenan sebagai Sarana Edukasi pada Tahun 1935 |Lulu Liani

Emen: "Har, naha silaing teu njaho, dewek meunang pagawean kamari?"

Machmoed: "Euleuh, gede bagdja silaing mah, make meunang pagawean, dewek mah nepi ka ajeuna masih keneh werkloos. Dimana digawe teh euj? Sabaraha meunang gadjih? Djeung koe naon ajeuna make kaloear?"

Emen: "Perkara gadjih tara tangtoe, saboelan dewek sok nampa 30 atawa 31 ...... powe! Ajeuna dewek kaloear tina pagawean sabab contractna geus beak!!”

Machmoed: "Har, naha dimana digawena silaing teh?"

Emen: "Di kantoor ...... H.V.B.!"

Machmoed: "......H.V.B.?"

Emen: "Heueuh di H.V.B. di Bantjeuj di Bandoeng, geuning di benteng, beurang peuting didjaga koe soldadoe njoren bedil!"

Machmoed: "Di Huis van Bewaring?!?"

Emen: "Tah eta, di hotel Perodio" (Sipatahoenan: Moerangkalih, Saptoe 6 Juli 1935, No.151 Lambaran ka 2)

\section{Pantas saja}

Ujang Emen di bui 7 bulan sebab mencuri ayam 7 ekor.

Setelah keluar dari bui, temannya bernama Machmud yang sudah lama tak bertemu dengannya bertanya: "Men, dari mana saja kamu udah lama gak kelihatan sama saya?"

Emen: "Har, emang kamu gak tahu, saya dapat kerjaan kemarin?"

Machmud: "Wah, bahagia benget kamu bisa dapat kerjaan, sampai sekarang saya malah masih nganggur. Di mana kerjanya? Berapa dapet gaji? Dan kenapa sekarang malah keluar?"

Emen: "Masalah gaji tidak tentu, sebulan biasa dapet 30 atau 31 .......... hari! Sekarang keluar dari kerjaan sebab kontraknya udah habis!!"’

Machmud: "Har, emang di mana kerjanya?"

Emen: "Di kantor ...... H.V.B.!"

Machmoed: "......H.V.B.?"

Emen: "Iya di H.V.B. di Banceuy di Bandung, ternyata pake benteng, siang malam dijaga petugas bersenjata"

Machmoed: "Di Huis van Bewaring?!?" 
Rubrik Moerangkalih dalam Surat Kabar Sipatahoenan sebagai Sarana Edukasi pada Tahun 1935 |Lulu Liani

Emen: "Nah itu, di hotel prodeo (penjara)" (Sipatahoenan: Moerangkalih, Sabtu 6 Juli 1935, No.151 Lembaran 2)

Kutipan di atas merupakan cerita pendek yang bertujuan untuk menghibur pembacanya. Dalam kutipan di atas diceritakan tentang Machmud yang bertanya pada Emen yang telah lama tidak berjumpa. Emen pun bercerita bahwa baru saja dibebaskan dari pekerjaan karena kontraknya habis. Tentu saja Machmud itu tidak menyangka bahwa Emen telah memiliki perkerjaan padahal ia saja masih pengangguran. Namun ternyata Emen itu bukan bekerja namun dipenjara sebab mencuri ayam.

8) Papatah dalam pupuh

Pupuh adalah karya sastra berupa puisi yang berasal dari Jawa yang terikat oleh jumlah baris tiap bait, jumlah suku kata dalam tiap baris, suku kata terakhir dari tiap akhir baris, tempat atau saat pernafasan (pedotan) serta watek atau karakter. ${ }^{21}$ Pupuh ini biasanya terpola oleh guru lagu dan guru wilangan. Dalam rubrik moerangkalih, pupuh biasanya berisi nasehat kehidupan.

\section{Sapoeloeh Papatah Kinanti}

1. Ieu sapoeloeh piwoeroek, anoe perloe pikeun diri, soepaja oelah katerap, koe roepa ${ }^{2}$ panjakit, noe matak tjilaka awak, oerang tetek hidji-hidji.

2. Leungeun salawasna koedoe, dikoembah masing beresih, oenggaloengal memeh neda, atawa moen entas ngising, koekoena koedoe disikat, koe sabab sok rea bacil.

3. Oerang dahar ambeh hiroep, djagdjag waringkas walagri, barang dahar tambarakan, eta teu njaah ka diri, poho kana kasehatan, noe matak salamet diri.

4. Pepeling anoe katiloe, poma oelah wani-wani, ngadaharan lalab atah, boeah ngora kitoe deui, kitoe sateh lamoen hajang, teu katerap koe panjakit.

5. Poma oerang oelah nginoem, soesoe atawana tjai, anoe teu di taheur heula, sabab masih loba bacil, anoe tatjan dipaehan, eta teh bibit panjakit.

${ }^{21}$ Soepandi, Atik, Kamus Istilah Karawitan Sunda, (Bandung: Satu Nusa, 1995), 168. 
Rubrik Moerangkalih dalam Surat Kabar Sipatahoenan sebagai Sarana Edukasi pada Tahun 1935 |Lulu Liani

6. Rea djalma noe kaliroe, njangka es maehan bacil, padahal eta teh salah, moen leungeun pinoeh koe bacil, dipake njabak es tea, nambahan tjilaka diri.

7. Kadaharan noe amoetjoej, djeung noe pangeunahna deui, henteu kabeh pangsehatna, aja noe matak balai, saperti beas noe ngeplak, ngadatangkaun biri-biri.

8. Hoentoe oge eta perloe, sabab parabot noe penting, pikeun djalan kadaharan, poma oerang koedoe apik, sikat oenggal entas dahar, pitjeunan sakabeh tjeuhil.

9. Oerang sing mindeng ngawoeroek, ka djongos reudjeung ka koki, oelah njerebetan wadah, koe serebet noe geus roedjit, lamoen henteu diwoeroekan, kasehatan oerang leungit.

10. Lamoen oerang arek batoek, baham toetoepan sing boeni, sabab moen henteu kitoe mah, bacil teh tangtoe baridjil, nepaan djalma noe aja, noe masih sehat walagri.

11. Di dinja tempatna ngoempoel, beurit insect reudjeung reungit, komo moen aja djarian, rea parab genah tjitjing, ka djalma nambahan bahja, nambahan deukeut panjakit.

E. Tams

Loba istri ngerik halis, malar djadi tambah geulis, eta teh teu hade pisan, tjek elmoening kasehatan.

(Sipatahoenan: Moerangkalih, Kemis 21 Februari 1935, No.41 Lambaran $\mathrm{ka}$ 1)

\section{Sepuluh pepatah kinanti}

1. Ini sepuluh pelajaran yang diperlukan untuk diri agar terbebas dari berbagai macam penyakit yang menyebabkan sakit, kita rincikan satusatu.

2. Tangan harus selalu bersih, dicuci hingga bersih, sebelum makan atau setalah buang hajat, kukunya harus di sikat, sebab pasti banyak bakteri.

3. Kita makan agar hidup, sehat wal'afiat, saat makan dengan rakus, berarti tidak menyayangi diri, lupa pada kesehatan, akan menyelamatkan diri.

4. Pengingat yang ketiga, hati-hati jangan berani-berani, memakan sayuran mentah, apalagi mangga muda, begitu juga jika ingin, tidak terkena penyakit. 
5. Hati-hati jangan sampai minum, susu atau air, yang tidak direbus dulu, sebab masih banyak bakteri, yang belum mati, itu adalah bibit penyakit.

6. Banyak orang yang keliru, menyangka es membunuh bakteri, padahal itu salah, jika tangan penuh dengan bakteri, dipakai menyentuh es, menambah celaka diri.

7. Makanan yang menggugah selera, dan yang paling enak juga, tidak semua menyehatkan, ada yang berbahaya, seperti beras yang putih, mendatangkan biri-biri.

8. Gigi juga perlu, sebab peralatan yang penting, untuk proses mencerna makanan, hati-hati harus teliti, sikat setiap beres makan, buang sisa makanan yang terselip di gigi.

9. Kita harus sering memberi tahu pada jongos dan juru masak, jangan membasuh wadah, dengan serbet yang sudah kotor, jika tidak diberi tahu, kesehatan kita hilang.

10. Jika kita akan batuk, tutup mulut hingga rapat, sebab jika tidak begitu, bakteri tentu saja akan keluar, menjangkiti orang yang ada, yang masih sehat wal'afiat.

11. Disitu tempatnya berkumpul, tikus serangga dan nyamuk, apalagi jika di tempat pembuangan sampah, banyak makanan enak berdiam, kepada manusia menambah bahaya, menambah dekat dengan penyakit.

E. Tams

Banyak perempuan mencukur alis, supaya menjadi tambah cantik,

itu sangat tidak baik, menurut ilmu kesehatan.

(Sipatahoenan: Moerangkalih, Kamis 21 Februari 1935, No.41 Lembaran 1)

Kutipan di atas merupakan pupuh yang berjudul "Sapoeloeh Papatah Kinanti" yang memiliki arti sepuluh pepatah kinanti. Kinanti disini berarti pupuh di atas memiliki karakter serta aturan pupuh kinanti. Tulisan tersebut memberikan pengajaran kepada pembaca mengenai sepuluh pelajaran yang diperlukan untuk diri agar terbebas dari berbagai macam penyakit. Mulai dari kebersihan badan hingga kebersihan tempat tinggal. Dalam kutipan di atas diceritakan secara rinci hal apa saja yang dapat dilakukan pembaca agar terbebas dari berbagai macam penyakit. Penjelasan dimulai dari kebersihan 
Rubrik Moerangkalih dalam Surat Kabar Sipatahoenan sebagai Sarana Edukasi pada Tahun 1935 |Lulu Liani

tangan, makanan dan minuman yang akan dicerna, kebersihan gigi, kebersihan alat makan, serta kebersihan tempat tinggal.

9) Kisah tokoh

Dalam kolom kisah tokoh ini para pembaca disajikan kisah-kisah tokoh yang memberikan sumbangsih cukup besar terhadap perkembangan kehidupan masyarakat khususnya kaum perempuan di Indonesia. Kisahkisah ini memiliki pesan moral yang besar mengingat perjuangan yang dilakukan mereka dalam mengangkat derajat kaum perempuan di Indonesia.

\section{Rd. Dewi Sartika}

\section{Entjep djeung Eulis!}

Minggoe toekang, mamang koengsi ngadadarkeun sadjarahna Raden Adjeng Kartini, ari ajeuna koe ingatan mamang, asa katjida hadena lamoen nataan para istri anoe arageung djasana pikeun hiroep koemboeh.

Di oerang, di kalangan bangsa Soenda, aja istri anoe perloe dikanjahokeun teh, nja eta Raden Dewi Sartika, Goeroe di sakola Raden Dewi di Bandoeng.

Bisa djadi oedjang djeung njai nja kitoe deui Entjep djeung Eulis geus aja anoe terang kana roepi andjeunna atawa geus aja oge anoe ngalaman sakola di sakola Raden Dewi, tapi koe lantaran ngarasa pereloe pikeun sarerea, ajeuna koe mamang baris diterangkeun koemaha kaajaan andjeunna pikeun kalangan oerang Soenda. Andjeunna teh, hidji sesepoeh Istri Soenda anoe mimiti moekakeun djalanna Istri Soenda sakoemna. Djadi ieu teh, lamoen di Djawa mah, nja Raden Adjeng Kartinina.

Moen teu salah, ngadegna ieu sakola anoe diadegkeun koe andjeunna teh, koe ingetan mamang geus 30 taoen. Loba moerid-moeridna anoe geus kalaloear sarta ajeuna geus tjarekel gawe di oenggal tempat.

Dina djaman katoekang, pangadjaranana di ieu sakola teh henteu make basa Walanda. Djadi ngan oekoer pangadjaran basa pikeun kaperloean soepaja bisa matja noelis djeung kaperloean roemah tangga (kawadjiban para Istri), tapi dina waktoe ieu mah, di eta sakola teh make diadjar basa Walanda sagala. Atoeh koe sabab kitoe, lamoen Eulis sakola ka dinja teh, hartina saroea bae djeung sakola ka Schakel atawa ampir mapakan ka H.I.S.

Tjindekna lamoen Eulis ngalaman sakola Djoeragan Dewi pikeun kaperloean Eulis di mana geus samawa, tjoekoep sakitoe mah.

Sakitoe pamanggih mamang tina kaajaan eta sakola teh. 
Rubrik Moerangkalih dalam Surat Kabar Sipatahoenan sebagai Sarana Edukasi pada Tahun 1935 |Lulu Liani

Koe seueur djasana tea, boh pikeun kamadjoean nagara atawa pikeun kamadjoean anoe djadi abdi-abdi. Djoeragan Dewi, ti pangagoeng parantos digandjar bintang perak malah anjar-anjar ieu, njaeta dina taoen (1934) andjeunna geus ngajakeun pesta pangeling-ngeling ngadegna eta sakola geus 30 taoen.

Dina ngadeg anoe sakitoe lilana, tetela ieu sakola pinanggih djeung kamadjoean, kamoeloesan anoe lain saeutik. Hartina gede mangpaatna pikeun sakoemna Istri Soenda.

[...]

Mang E.M.

(Sipatahoenan: Moerangkalih, Saptoe 13 April 1935, No.84 Lambaran ka 1)

\section{Rd. Dewi Sartika}

\section{Entjep dan Eulis!}

Minggu kemarin, mamang telah menjelaskan sejarahnya Raden Ajeng Kartini, sekarang berdasarkan ingatan mamang, alangkah baiknya jika kita membahas para perempuan yang besar jasanya terhadap pertumbuhan masyarakat.

Di wilayah kita, di kalangan bangsa Sunda, ada perempuan yang perlu kita ketahui, yaitu Raden Dewi Sartika, guru di sekolah Raden Dewi di Bandung.

Bisa jadi kalian sudah mengetahui wajah beliau atau ada yang sudah mengalami pembelajaran di sekolah Raden Dewi, tapi karena merasa perlu akan kemaslahatan bersama, sekarang mamang akan menerangkan bagaimana keadaan beliau di kalangan orang Sunda. Beliau adalah salah satu sesepuh perempuan Sunda yang pertama membukakan jalan bagi seluruh perempuan Sunda. Jadi jika di Jawa itu ya Raden Ajeng Kartini.

Jikalau tak salah, berdirinya sekolah yang didirikan oleh beliau ini menurut ingatan mamang telah berusia 30 tahun. Banyak murid-muridnya yang sudah lulus serta memiliki pekerjaan di berbagai bidang.

Pada jaman sebelumnya, pelajaran di sekolah ini tidak menggunakan bahasa Belanda. Jadi hanya pengajaran bahasa untuk keperluan sehari-hari supaya bisa baca tulis dan keperluan rumah tangga (kewajiban para Istri), tapi sekarang di sekolah tersebut sudah mempelajari bahasa Belanda. oleh sebab itu jika kalian sekolah di sana, artinya sama seperti sekolah di sekolah Schakel atau hampir menyerupai H.I.S. 
Singkatnya jika kalian mengalami sekolah di sekolah Juragan Dewi untuk keperluan nanti di mana kalian sudah dewasa dan berumah tangga sudah cukup.

Demikianlah apa yang mamang tahu dari keadaan sekolah itu.

Banyaknya jasa beliau untuk kemajuan negara atau untuk kemajuan yang menjadi pesuruh. Juragan Dewi, telah dianugerahi bintang perak bahkan baru-baru ini yaitu tahun 1934, beliau sudah mengadakan peringatan berdirinya sekolah yang telah 30 tahun.

Dari lamanya sekolah berdiri tentu saja sekolah ini sudah mengalami kemajuan yang tidak sedikit. Artinya banyak manfaat yang ditebarkan bagi seluruh perempuan Sunda.

[...]

Mang E.M.

(Sipatahoenan: Moerangkalih, Sabtu 13 April 1935, No.84 Lembaran 1)

Kutipan di atas merupakan kisah tokoh yang berjudul Rd. Dewi Sartika. Beliau adalah sosok perempuan Sunda yang inspiratif serta memberikan teladan bagi para perempuan Indonesia secara umum. Dari kisah keteladanan Rd. Dewi Sartika, para pembaca disajikan bagaimana perjuangan beliau dari awal hingga akhirnya mencapai tujuannya memajukan para perempuan dengan mendirikan sekolah Istri. Pesan moral yang dapat pembaca ambil dari kisah ini yaitu sebagai seorang perempuan kita harus berpegang teguh pada pendirian, serta memulai dengan aksi yang nyata untuk perubahan tersebut.

\section{Kesimpulan}

Berdasarkan pembahasan di atas maka dapat disimpulkan sebagai berikut:

1. Sipatahoenan lahir dari hasil konferensi Pagoejoeban Pasoendan pada tanggal 25-26 Desember 1922 untuk kemudian pendiriannya dibebankan kepada Pagoejoeban Pasoendan Cabang Tasikmalaya dibawah pimpinan Ahmad Atmaja dengan menggunakan modal awal pinjaman dari dana beasiswa Pasoendan sekitar Rp 3.500. Pada tanggal 29 April 1931 pengurus Pagoejoeban Pasoendan cabang Tasikmalaya mengambil keputusan untuk menyerahkan Sipatahoenan kepada Pengurus Besar 
Pagoejoeban Pasoendan di Bandung. Di bawah kepemimpinan pengurus besar ini diterbitkan rubrik khusus yang diperuntukkan bagi anak-anak yang dinamakan Moerangkalih. Tujuan diterbitkannya moerangkalih adalah untuk menyediakan bacaan yang layak bagi anak-anak pada masa itu.

2. Unsur edukasi yang dapat ditemukan dalam rubrik moerangkalih diantaranya yaitu pertama, mengedukasi pembacanya agar lebih menghargai kehidupan serta jalan mencapai kemuliaan hidup itu sendiri seperti memahami apa itu cageur, bageur, pinter. Kedua, menginformasikan penemuan-penemuan baru pada masa itu. Ketiga, pembaca dapat mengambil hikmah untuk jangan pernah terburu-buru menilai sesuatu karena belum tentu terbukti kebenarannya. Keempat, pembaca dapat melihat bagaimana perbuatan buruk yang dilakukan seseorang akan kembali kepadanya. Kelima, pembaca diberi nasehat mengenai hal-hal yang diperlukan untuk diri agar terbebas dari berbagai macam penyakit. Mulai dari kebersihan badan hingga kebersihan tempat tinggal. Keenam, pembaca dapat mengambil hikmah dari kisah tokoh bahwa sebagai seorang perempuan kita harus berpegang teguh pada pendirian, serta memulai dengan aksi yang nyata untuk perubahan tersebut. 
Rubrik Moerangkalih dalam Surat Kabar Sipatahoenan sebagai Sarana Edukasi pada Tahun 1935 |Lulu Liani

\section{Reference}

\section{Buku}

I Ketut Ardhana. 2009. Pergerakan Nasional dan Sistem Kepartaian, Indonesia dalam Arus sejarah Jilid 5 : Masa Pergerakan Kebangsaan. Jakarta: Ichtiar Baru van Hoeve.

R. Djaka Soeryawan. 1990. Sejarah Berdirinya Paguyuban Pasundan. Bandung: Lembaga Kebudayaan Universitas Pasundan.

Gottschalk, Louis. 1985. Mengerti Sejarah. Jakarta: UI Press.

Sulasman. 2014. Metodologi Penelitian Sejarah. Bandung: Pustaka Setia.

Abdurrahman, Dudung. 1999. Metode Penelitian Sejarah. Jakarta: PT Logos Wacana Ilmu.

Kuntowijoyo. 2013. Pengantar Ilmu Sejarah. Yogyakarta: Tiara Wacana.

Sjamsuddin, Helius. 2007. Metodologi Sejarah. Yogyakarta: Penerbit Ombak.

McQuail, Denis. 2011. Teori Komunikasi Massa. Jakarta: Penerbit Salemba Humanika.

Lubis, Nina. 2003. SI JALAK HARUPAT: Biografi R. Oto Iskandar di Nata (1897-1945). Jakarta: Gramedia Pustaka Utama.

Lubis, Nina Herlina. 2007. Metode Sejarah. Jawa Barat: YMSI.

Effendy, Onong Uchjana. 2007. Ilmu Komunikasi (Teori dan Praktek). Bandung: PT. Remaja Rosdakarya.

Pusat Bahasa. 2007. Kamus Besar Bahasa Indonesia. Jakarta: Balai Pustaka. Soepandi, Atik. 1995. Kamus Istilah Karawitan Sunda. Bandung: Satu Nusa. Surat Kabar/Koran:

"Toetoeroetjingan" dalam Sipatahoenan, Kamis, 3 Januari 1935. Bandung.

"Toetoeroetjingan" dalam Sipatahoenan, Kamis, 10 Januari 1935. Bandung.

"Patjadoean" dalam Sipatahoenan, Kamis, 30 Januari 1935. Bandung.

"Boedak bangor" dalam Sipatahoenan, Kamis, 24 Januari 1935. Bandung.

"Koedoe sagala wajahna" dalam Sipatahoenan, Kamis, 7 Februari 1935. Bandung.

"Sato leuweung" dalam Sipatahoenan, Kamis, 26 Februari 1935. Bandung.

"Salah mangarti" dalam Sipatahoenan, Kamis, 7 Februari 1935. Bandung.

"Sapoeloeh papatah kinanti" dalam Sipatahoenan, Kamis, 21 Februari 1935.

Bandung.

"Rd. Dewi Sartika" dalam Sipatahoenan, Sabtu, 13 April 1935. Bandung.

"Pibekeleun hiroep" dalam Surat kabar Sipatahoenan, Sabtu, 15 Juni 1935.

Bandung.

"Paingan" dalam Sipatahoenan, Sabtu, 6 Juli 1935. Bandung.

"Roepa-roepa kanjaho" dalam Sipatahoenan, Sabtu, 3 Agustus 1935. Bandung.

"Sipatahoenan: Riwayat Koran Tiga Zaman” dalam Pikiran Rakyat, Selasa, 3 Februari 2015. Bandung. 
Rubrik Moerangkalih dalam Surat Kabar Sipatahoenan sebagai Sarana Edukasi pada Tahun 1935 |Lulu Liani

"Digaji Hatur Nuhun" dalam Pikiran Rakyat, Rabu, 4 Februari 2015. Bandung.

“Kritik Sekaligus Toleran” dalam Pikiran Rakyat, Minggu, 8 Februari 2015. Bandung.

\section{Internet:}

Admin, "17 Jenis Pupuh Sunda, Karya Seni Sastra yang Perlu Terus Dilestarikan" dalam https://kuyahejo.com/pupuh-sunda/. Diakses pada 22 Juli 2020 pukul 12.24 WIB.

Anonim, "Peranan Pers dalam Pergerakan Nasional Indonesia" dalam www.patikab.go.id/v2/id/2013/04/01/peranan/pers/dalam/pergerakan Inasional/indonesia/. Diakses pada 15 Januari 2020 pukul 08.02 WIB. 
Rubrik Moerangkalih dalam Surat Kabar Sipatahoenan sebagai Sarana Edukasi pada Tahun 1935 |Lulu Liani 